in the region where the sample was obtained, and is recognized under the Native Title Act 1993. The directors are elected by GLSC members, and membership is open to all Aboriginal residents of the region. In granting their permission for the research, the board exercised properly defined moral, cultural and legal authority to speak on behalf of the Aboriginal people there.

Most research - be it sociological, historical or genetic, or even political polling - extrapolates from a sample to draw conclusions. Participants are rarely expected to seek consent from their entire group before giving up information.

Because the hair sample was almost certainly given to British ethnologist Alfred Cort Haddon voluntarily in the early 1920 s, this example of an informal exchange between an Aboriginal person and a researcher does not provide a model for all such exchanges in the future. These should be underpinned by a standard indicating that free, prior and informed consent was sought from the proper people. Craig Muller Goldfields Land and Sea Council, Perth, Western Australia, Australia. craig.muller@glc.com.au

\section{Give more priority to phosphorus studies}

I agree with James Elser and Elena Bennett that we should recycle phosphorus (Nature 478, 29-31; 2011). However, there are situations in which the natural recycling of phosphorus is not ecologically desirable.

As the authors note, excess phosphorus in water bodies can feed algal blooms and create anoxic zones. What is less well known is that these waters can become permanent dead zones, stuck in an oxygen-deprived, nutrient-rich state. This happens when the algae die, sink and are decomposed by anaerobic bacteria that need only limited amounts of phosphorus. Most of the algal phosphorus is released back into the water to feed further blooms. In the Baltic Sea, for example, reductions in phosphorus pollution from rivers have not yet led to ecosystem recovery because of this effect.

We have disturbingly little insight into major phosphorus fluxes in the marine realm. This is the legacy of decades of research priority being given to the microbial complexities of the nitrogen cycle over the methodologically challenging investigation of phosphorus cycling.

Caroline P. Slomp Utrecht University, the Netherlands. c.p.slomp@uu.nl

\section{Boost resilience to tackle mental illness}

An economically efficient way of tackling the enormous social and economic costs of mental ill health (Nature 477, 132 and 478,$15 ; 2011$ ) would be to boost 'resilience' to mood disorders.

Mentally healthy individuals often show a positive affective bias because their processing of negative information is inhibited. This effect, possibly mediated by the neuromodulator serotonin, promotes resilience by dampening the stress associated with negative life experiences.

Devising ways to promote such resilience in healthy individuals could help to prevent chronic stress-related brain disorders, saving huge amounts of money and heartache every year. Oliver J. Robinson National Institute of Mental Health, Bethesda, Maryland, USA. robinsonoj@mail.nih.gov

Disclaimer: Views presented in this Correspondence are solely those of the author and do not necessarily represent the views of the US federal government.

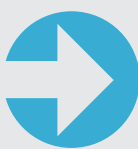

\section{NATURE'S READERS COMMENT ONLINE}

Selectedresponses

to 'Fund people not

projects' by John P. A. Ioannidis (Nature 477, 529-531; 2011).

\section{Yiding Zhao says:}

'Fund people not projects' was once the model used in China, but major international journals frowned on it because it risked creating Xue ba (scientific autocracy that suppresses others' ideas). So we worked hard to adapt the grant-based model. Now you are telling us the grant-based model is worse? yidingzhao@pku.edu.cn

\section{Ken Whitmire says:}

A way to fund people rather than projects would be to allocate money directly to individual graduate students and postdocs through fellowships, instead of funnelling it through a principal investigator's grant. This redirection wouldn't cost the system any more money, and it would make it clear to nonscientists that fellowships are funding the training of a highly skilled technical workforce, as well as helping a research enterprise. Students would have more independence in choosing an adviser and advisers would be under less pressure to raise huge sums of money to support an active research group. whitmir@rice.edu

\section{Sander Heinsalu says:}

Funding models have tradeoffs. Detailed checks create bureaucracy, but avoid misuse of money. Specific goals limit creativity, but avoid funding less useful projects. I would like to see scientific evidence on which funding models generate better output - although the best definition of output is also debatable.

sanderheinsalu@hot.ee

\section{Adrian Barnett says:}

One option is to fund projects retrospectively, with money being handed out for work delivered (including papers, policy changes, improvements in health), rather than for promises made in grant applications. Most current grant systems are heavily biased towards senior staff, but this scheme would work irrespective of applicants' status. The process would be less burdensome for researchers because it would involve gathering their existing evidence and costs. a.barnett@qut.edu.au

\section{Craig Macfarlane says:}

The funding model is largely irrelevant - what really matters is the amount of money. Whatever the system is, scientists are smart enough to learn to play it, and it will be dominated by established players who are closest to its centre. The only solutions are for developed countries to increase public funding for research to ensure that it is not just the heavyweights who receive grants, and to support more public-good research. Anything else is just fiddling at the margins. Until that happens (when hell freezes over perhaps), get used to things the way they are. fisheye@iinet.net.au

To join this debate, go to http://go.nature.com/ciahh5. 